09.3;09.4;09.7;13.1;13.3

\title{
Лазерная модификация титановой пленки на поверхности оптических волноводов в ниобате лития
}

\author{
(C) А.В. Тронев ${ }^{1}$, М.В. Парфенов ${ }^{1,2}$, Н.А. Соломонов ${ }^{3}$, А.М. Ионов ${ }^{4}$, С.И. Божко ${ }^{4}$, \\ И.В. Ильичев ${ }^{1}$, П.М. Агрузов ${ }^{1}$, А.В. Шамрай ${ }^{1}$ \\ ${ }^{1}$ Физико-технический институт им. А.Ф. Иофрфе РАН, Санкт-Петербург, Россия \\ ${ }^{2}$ Санкт-Петербургский политехнический университет Петра Великого, Санкт-Петербург, Россия \\ ${ }^{3}$ Санкт-Петербургский государственный электротехнический университет „ЛЭТИ“, Санкт-Петербург, Россия \\ ${ }^{4}$ Институт фризики твердого тела РАН, Черноголовка, Московская обл., Россия \\ E-mail: trone2008@ya.ru
}

Поступило в Редакцию 20 мая 2020г.

В окончательной редакции 8 июня 2020г.

Принято к публикации 8 июня 2020г.

Показано, что лазерная модификация нанометровой титановой пленки может быть использована для точного управления уровнем потерь в оптических волноводах на подложках ниобата лития. Теоретические оценки изменения погонных потерь на уровне $0.95 \mathrm{~dB} / \mathrm{mm}$ подтверждены экспериментами по локальной лазерной модификации с использованием излучения на длине волны $976 \mathrm{~nm}$ с пороговой интенсивностью $1 \mathrm{~kW} / \mathrm{mm}^{2}$. Предложенная методика может быть эффективно использована для прецизионной подгонки характеристик интегрально-оптических устройств, например контраста модуляции модуляторов Маха-Цендера.

Ключевые слова: интегральная оптика, лазерная модификация, титановая пленка, оптический волновод, ниобат лития.

DOI: 10.21883/PJTF.2020.17.49896.18387

Интегральная оптика на подложках ниобата лития является одной из базовых технологических платформ для создания высокочастотной оптоэлектроники [1]. Новые практические приложения, связанные с квантовыми информационными технологиями [2] и прецизионными оптическими измерениями [3], выдвигают очень жесткие требования к характеристикам интегрально-оптических схем на подложках ниобата лития. Достижимые предельные характеристики во многом определяются технологическими погрешностями, связанными с вариациями условий формирования волноводных структур и конечной точностью фотолитографии, использующейся для формирования топологии волноводных схем. Например, контраст модуляции сигнала амплитудных модуляторов (отношение оптических мощностей в максимуме и минимуме прохождения), связанный с балансировкой плеч интерферометра Маха-Цендера, напрямую зависит от вариации потерь в оптических волноводах и точности изготовления волноводных делителей оптической мощности. Современный технологический уровень позволяет воспроизводимо получать модуляторы с контрастом модуляции до $30 \mathrm{~dB}$, в то время как современные практические приложения требуют $50 \mathrm{~dB}$ и выше [4].

Ранее нами были опубликованы исследования, посвященные точной фоторефрактивной подстройке коэффициентов деления оптических волноводных разветвителей [5-7]. Недостатком фоторефрактивного воздействия является быстрая релаксация наведенного локального изменения показателя преломления. Для получения стабильного во времени изменения характеристик оптических волноводов необходимо использовать не всегда пригодные для проведения на готовом устройстве методы термического фиксирования [8], лазерной абляции [9] или весьма сложный для технической реализации, требующий использования мощных фемтосекундных импульсов метод прямой лазерной записи [10].

Цель данного исследования - разработать метод лазерного управления характеристиками оптических волноводов на подложках ниобата лития, простой в технической реализации и удобный для применения на финальном этапе технологического цикла - сборке в корпус. Кроме того, разрабатываемый метод должен обеспечивать стабильную во времени подстройку интегральнооптических схем.

Известно, что тонкая металлическая пленка оказывает заметное воздействие на характеристики оптических волноводов. Например, были продемонстрированы высокий контраст выделения ТЕ-поляризационной моды за счет возбуждения плазмон-поляритонов [11] и подстройка коэффициента деления направленного ответвителя за счет изменения постоянной распространения [12]. В наших исследованиях мы интересовались локальным управлением потерями в оптических волноводах, а также возможностью лазерной модификации металлической пленки, поэтому рассматривались пленки предельно малых толщин (менее $10 \mathrm{~nm})$. В качестве материала пленки был выбран титан, поскольку он обладает хорошей адгезией к ниобату лития, имеет большую действительную часть комплексного показателя преломления $n_{\mathrm{Ti}}^{\prime} \approx 3.68$ на длине волны $1550 \mathrm{~nm}$, что обеспечивает высокую эффективность взаимодействия с поляризационными волноводными модами в ниобате ли- 

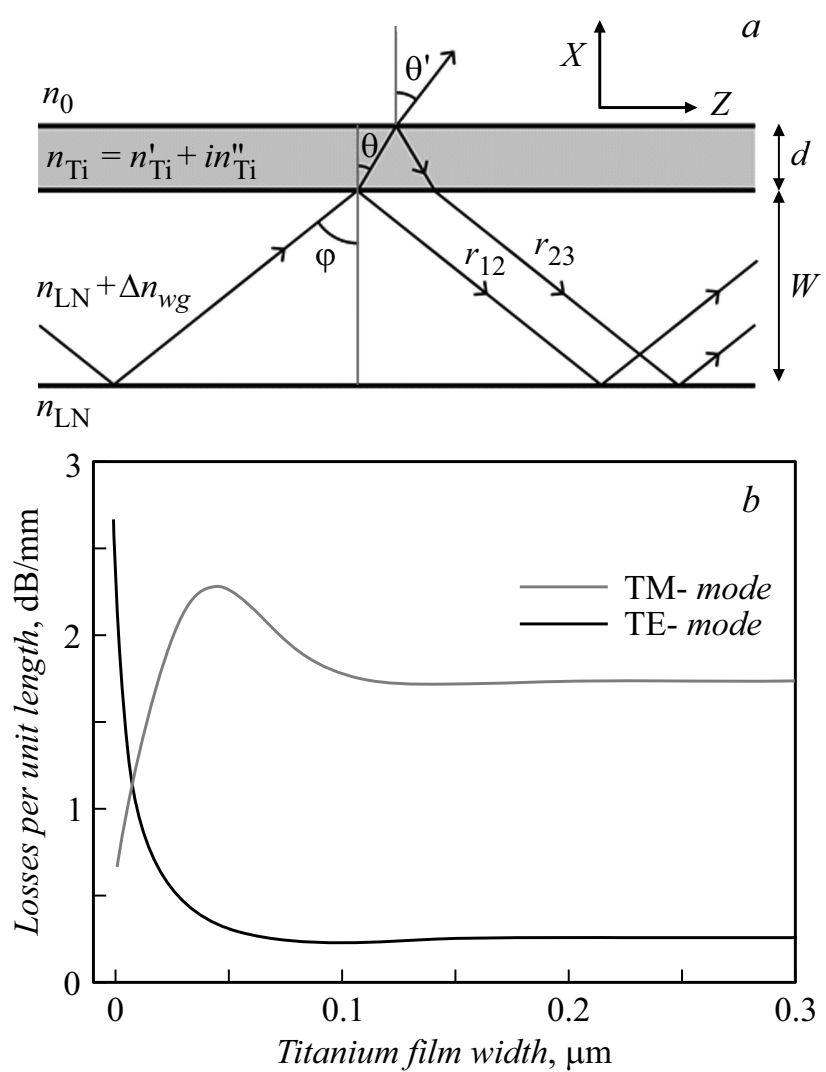

Рис. 1. Влияние тонкой пленки титана на поверхности волновода на величину оптических потерь. $a$ - лучевая модель (пояснение в тексте); $b-$ зависимость погонных оптических потерь на длине волны $1550 \mathrm{~nm}$ от толщины металлической пленки титана на поверхности оптического волновода $(W=7 \mu \mathrm{m}, N A \approx 0.12)$ для двух ортогональных поляризационных мод.

тия, а также легко окисляется под действием лазерного излучения [13].

Оценка оптических потерь, индуцированных нанометровой титановой пленкой, была сделана с использованием упрощенной лучевой модели (рис. 1,a). Значительные потери возникают при малых толщинах металлической пленки, меньших, чем скин-слой, за счет нарушения полного внутреннего отражения и утечки волноводной моды через металлическую пленку. Коэффициент потерь в волноводе описывается выражением

$$
\alpha=\frac{1-R_{w} R_{m}}{2 W \operatorname{tg} \varphi},
$$

где $R_{w}=1$ соответствует полному внутреннему отражению на границе подложка-волновод, а отражение от металлической пленки $R_{m}$ зависит от ее толщины как

$$
\begin{gathered}
R_{m}=\left|\frac{r_{12}+r_{23} \exp (i \delta)}{1+r_{12} r_{23} \exp (i \delta)}\right|^{2}, \\
\delta=2 \frac{2 n_{\mathrm{Ti}} d}{\lambda} \cos \theta,
\end{gathered}
$$

где $n_{\mathrm{Ti}}=n_{\mathrm{Ti}}^{\prime}+i n_{\mathrm{Ti}}^{\prime \prime}-$ комплексный показатель преломления пленки, $r_{12}$ и $r_{23}-$ коэффициенты отраже- ния от границ металлической пленки, рассчитанные по формулам Френеля. Для теоретической оценки были использованы характерные параметры для одномодовых титан-диффузных волноводов на подложках $X$-среза ниобата лития: эффективная толщина $W \approx 7 \mu \mathrm{m}$, числовая апертура $N A \approx 0.12 \approx \pi / 2-\varphi[\mathrm{rad}]$ и эффективные показатели преломления для ортогональных поляризаций $\left(n_{\mathrm{LN}}^{\mathrm{TE}} \approx 2.14, n_{\mathrm{LN}}^{\mathrm{TM}} \approx 2.21\right)$. Отметим, что пленка по-разному влияет на потери двух собственных ортогонально поляризованных мод оптического волновода (рис. $1, b)$. Для ТМ-поляризации потери растут с увеличением толщины пленки, при толщине пленки около $40 \mathrm{~nm}$ наблюдается небольшой максимум, связанный с плазмон-поляритонным резонансом. Для ТЕ-моды потери резко падают с ростом толщины пленки и при толщине более $100 \mathrm{~nm}$ становятся меньше $0.3 \mathrm{~dB} / \mathrm{mm}$. Именно влияние на потери ТЕ-моды наиболее интересно, поскольку данная поляризация имеет более высокий электрооптический коэффициент и используется в электрооптических модуляторах.

Экспериментальные исследования лазерной модификации титановой пленки проводились на образцах с прямым канальным волноводом, изготовленным методом термической диффузии титана [14] на подложке ниобата лития $X$-среза. Пленка металлического титана толщиной $5 \mathrm{~nm}$ была нанесена на поверхность образцов методом магнетронного напыления. Дополнительные погонные потери, вносимые пленкой, составили 0.95 и $1.3 \mathrm{~dB} / \mathrm{mm}$ для ТЕ- и ТМ-поляризационных мод соответственно, что хорошо согласуется с результатами, полученными на основе упрощенной лучевой модели. Был проведен эксперимент по химическому травлению пленки. В ходе травления наблюдались быстрый рост оптических потерь в волноводе для ТЕ-моды по мере уменьшения толщины пленки и скачкообразное уменьшение потерь при полном вытравливании пленки, что также согласуется с характером зависимости, полученной из расчета по лучевой модели.

Лазерная модификация пленки проводилась с использованием полупроводникового лазера накачки для волоконных эрбиевых усилителей $(976 \mathrm{~nm}, 600 \mathrm{~mW})$. Волоконный выход с диаметром пятна на выходе из волокна $\sim 10 \mu \mathrm{m}$ обеспечивал довольно высокую интенсивность на поверхности пленки $\left(\sim 1 \mathrm{~kW} / \mathrm{mm}^{2}\right)$ и использовался как оптический зонд. Точное позиционирование зонда относительно оптического волновода осуществлялось путем перемещения образца, закрепленного на моторизированном трехкоординатном позиционере. В области воздействия оптического излучения наблюдается увеличение прозрачности металлической пленки в видимом диапазоне (рис. 2,a). Для того чтобы область оптической модификации гарантированно покрывала оптический волновод, оптический зонд сканировал в направлении, перпендикулярном направлению волновода, на дистанцию $50 \mu \mathrm{m}$ со скоростью $\sim 1 \mathrm{~mm} / \mathrm{s}$. Единичный проход формировал в пленке просветленный в видимом диапазоне участок шириной $\sim 6 \mu \mathrm{m}$. Протяженные участки модифицированной 

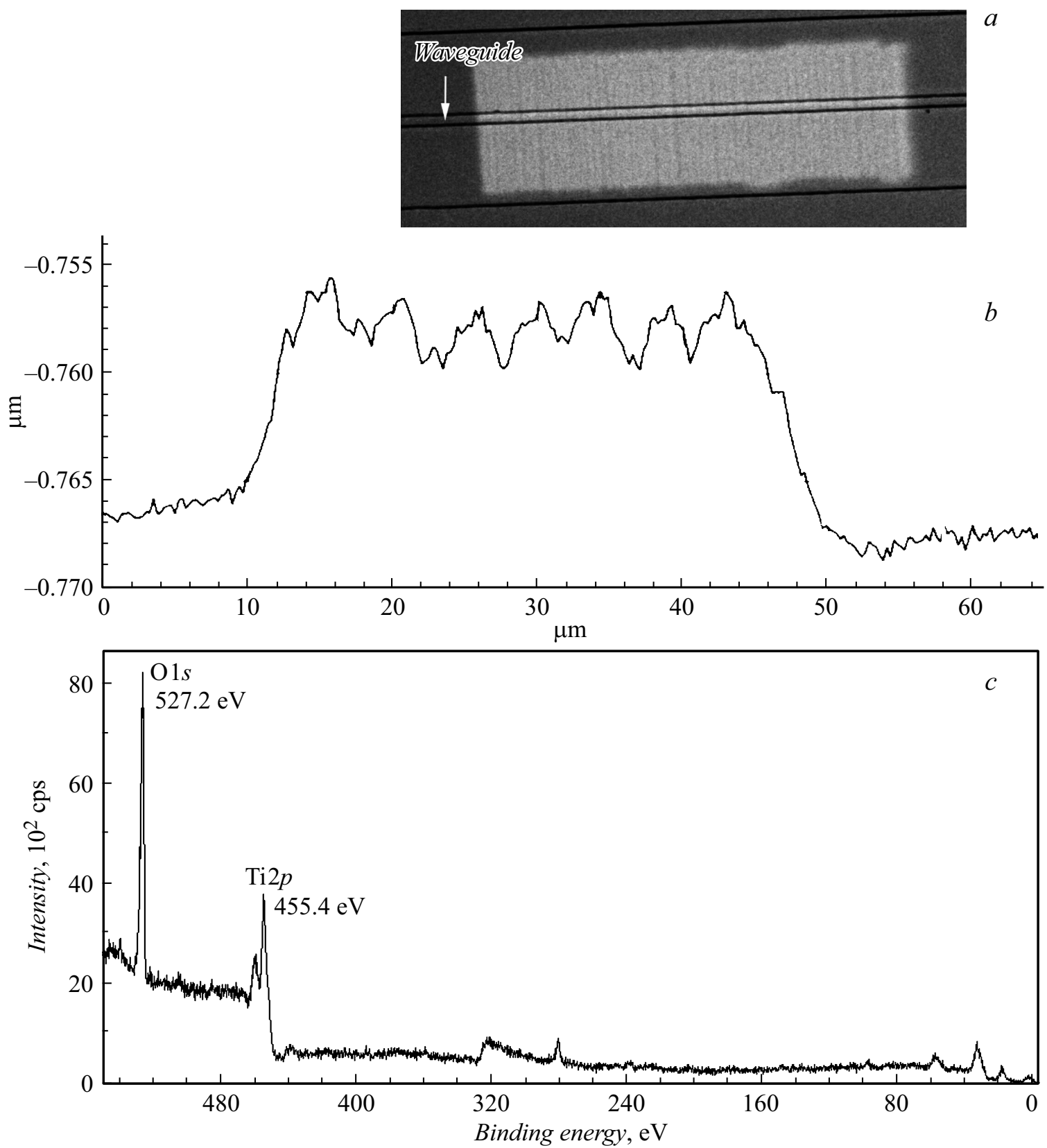

Рис. 2. Результаты оптической модификации пленки титана. $a$ - изображение, полученное с помощью оптического микроскопа; $b-$ профиль с оптического профилометра со следами зигзагообразного сканирования; $c-$ РФЭС модифицированной титановой пленки.

пленки на поверхности канального оптического волновода были получены зигзагообразным сканированием со смещением зонда вдоль волновода с шагом $10 \mu \mathrm{m}$. Оптическая модификация титановой пленки приводила к уменьшению погонных волноводных потерь на 1.05 и $1.4 \mathrm{~dB} / \mathrm{mm}$ для ТЕ- и ТМ-поляризационных мод соответственно. Большее значение погонных потерь, полученное при лазерной засветке пленки, по сравнению с таковыми при химическом травлении связано с меньшей точностью измерения длины волновода с модифицированным покрытием из-за градиентной засветки на границе.
Исследования модифицированных участков пленки с помощью оптического профилометра, а также электронного и атомно-силового микроскопов показали, что в области модификации наблюдается вспучивание поверхности на высоту порядка $15 \mathrm{~nm}$ (рис. 2,b) относительно незасвеченной поверхности покрытия. Рентгеновская фотоэлектронная спектроскопия (РФЭС) выявила спектральные линии O1s и Тi2 $p$ с энергиями связи, характерными для оксидов титана, что свидетельствует о формировании оксида титана в областях модификации (рис. 2,c). Отметим, что отсутствие линий ниобия в спектре демонстрирует сплошность титановой пленки. 


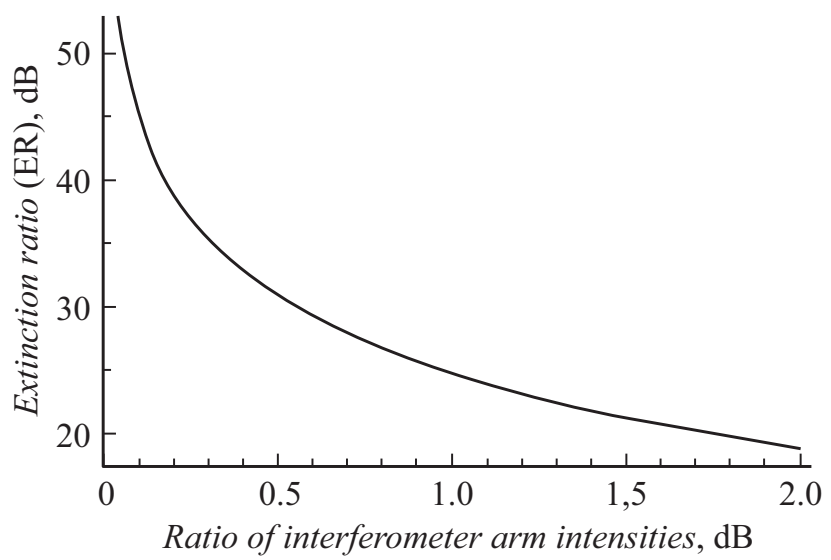

Рис. 3. Расчетная зависимость контраста модуляции выходного сигнала модулятора Маха-Цендера от дисбаланса оптической мощности в плечах интерферометра.

Предложенный метод управления оптическими потерями может быть использован для балансировки оптической мощности в плечах модулятора Маха-Цендера и повышения контраста модуляции его выходного сигнала $\mathrm{ER}$, величина которого с учетом дисбаланса мощностей в плечах интерферометра выражается в децибелах как

$$
\begin{gathered}
\mathrm{ER}=10 \lg \left(\frac{1+m}{1-m}\right), \\
m=\frac{2 \sqrt{10^{0.1 \Delta L}}}{1+10^{0.1 \Delta L}},
\end{gathered}
$$

где $\Delta L-$ соотношение оптических мощностей в плечах интерферометра, выраженное в децибелах, $m$ - видность интерферограммы интерферометра Маха-Цендера. Теоретическая зависимость (рис. 3) показывает, что у коммерчески доступных модуляторов с контрастом модуляции $\mathrm{ER}=30 \mathrm{~dB}$ дисбаланс между плечами интерферометра $\Delta L$ составляет $\sim 0.6 \mathrm{~dB}$. Экспериментально продемонстрированная точность управления потерями составляет $\sim 10^{-3} \mathrm{~dB}$ при единичном проходе зондом поперек волновода. Поэтому можно ожидать, что предложенный метод позволит повысить контраст модуляции до уровня $70 \mathrm{~dB}$. Отметим, что для балансировки достаточно предусмотреть в топологии модулятора в каждом плече интерферометра Маха-Цендера область, покрытую пленкой титана длиной $0.6 \mathrm{~mm}$, вносящую дополнительные потери $\sim 0.6 \mathrm{~dB}$, сопоставимые с дисбалансом для легко получаемого контраста модуляции $30 \mathrm{~dB}$.

Таким образом, была продемонстрирована возможность использования предложенного метода для высокоточной подстройки оптических потерь в оптических волноводах на подложке ниобата лития. Формирование устойчивого оксида титана в области модификации, а также его частичное проникновение в подложку свидетельствуют о стабильности выполненной подстройки.

\section{Благодарности}

В работе использовано оборудование ЦКП ИФТТ PAH.

\section{Финансирование работы}

Финансирование исследования осуществлялось из средств гранта Российского научного фонда (проект № 19-19-00511).

\section{Конфликт интересов}

Авторы заявляют, что у них нет конфликта интересов.

\section{Список литературы}

[1] Петров В.М., Шамрай А.В. Интерференция и дифракция для информационной фотоники. СПб.: Лань, 2019. 460 с.

[2] Alibart O., D'Auria V., Micheli M., Doutre F., Kaiser F., Labonté L., Lunghi T., Picholle E., Tanzilli S. // J. Opt. 2016. V. 18. P. 104001.

[3] Johnson L.M. Fiber optic sensors: an introduction for engineers and scientists / Eds E. Udd, W.B. Spillman. John Wiley Sons, 2011. P. 87-118.

[4] Yamaguchi V.Y., Nakajima S., Kanno A., Kawanishi T., Izutsu M., Nakajima H. // Jpn. J. Appl. Phys. 2014. V. 53. P. 08MB03. DOI: 10.7567/JJAP.53.08MB03

[5] Парфенов М.В., Тронев А.В., Ильичев И.В., Агрузов П.М., Шамрай А.В. // Письма в ЖТФ. 2019. Т. 45. В. 5. С. 3-5.

[6] Парфенов М.В., Тронев А.В., Ильичев И.В., Агрузов П.М., Шамрай А.В. // Письма в ЖТФ. 2020. Т. 46. В. 1. С. 8-11.

[7] Parfenov M., Tronev A., Ilichev I., Agruzov P., Shamrai A. // Appl. Phys. B. 2020. V. 126. P. 93. DOI: $10.1007 / \mathrm{s} 00340-020-07440-5$

[8] Grachev A.I., Chamrai A.V., Petrov M.P. // OSA TOPS. 2011. V. 62. P. 203-211.

[9] Chen C.-C., Portea H., Goedgebuera J.-P., Armbrustera V., Ferrierea R. // Opt. Laser. Technol. 2002. V. 34. P. 453-455.

[10] Bazzan M., Sada C. // Appl. Phys. Rev. 2015. V. 2. P. 040603. DOI: $10.1063 / 1.4931601$

[11] Ильччев И.В., Тогузов Н.В., Шамрай А.В. // Письма в ЖТФ. 2009. Т. 35. В. 17. C. 97-103.

[12] Mikami O., Noda J. // Appl. Phys. Lett. 1978. V. 33. P. 856858. DOI: $10.1063 / 1.90213$

[13] Arkadiusz J.A., Skowronski L., Trzcinski M., Kinzhybalo V.V., Lazarek K.L., Abramski K.M. // Appl. Surf. Sci. 2015. V. 325. P. 217-226.

[14] Караваев П.М., Ильччев И.В., Агрузов П.М., Тронев А.В., Шамрай А.В. // Письма в ЖТФ. 2016. Т. 42. В. 10. С. 33 39. 